\title{
EDITORIAL
}

\section{A 40 AÑOS DE DEVALUACIONES, CRISIS RECURRENTES Y DESREGULACIONES}

“Adiós represión financiera. ¡Qué tal, crack financiero!” de Carlos F. Díaz Alejandro es un trabajo de enseñanza para aquellos países que han implementado políticas de desregulación y liberalización financiera, en aras de un financiamiento al desarrollo más incluyente y que han llegado no sólo a crisis financieras, cuyo efecto ha provocado cambios estructurales de sus economías en los circuitos económicos y financieros a nivel mundial.

Las crisis recurrentes presentadas en todos los países desde los años setenta hasta la actualidad, muestran la transición de los sistemas financieros regulados a sistemas financieros nacionales insertos en los circuitos financieros globales. Más allá de ello, la respuesta de las políticas públicas ante el crack financiero, resultado de los procesos de desregulación y liberalización financiera, han subsumido a las políticas monetarias, fiscales y financieras a los intereses de los mercados y a un proceso creciente de financiarización.

A la luz de 40 años de devaluación de las monedas y una vez roto el principio de tipos de cambio fijo del Sistema Monetario de Bretton Woods, el precio de las exportaciones de los países subdesarrollados ha estado determinado por las fluctuaciones del tipo de cambio de la moneda nacional frente al equivalente internacional, así como por la tasa de interés cuya referencia principal está determinada por la Reserva Federal de los Estados Unidos (Fed).

Es así como desde la primera devaluación del tipo de cambio en México hasta las recientes fluctuaciones del peso frente al dólar, referente al equivalente general internacional, nuestro país paulatinamente ha ido subsumiendo el corazón del desarrollo y crecimiento económico a los organismos financieros internacionales. Hay que destacar, entonces, que quien ha fijado durante más de 40 ańos la política monetaria ha sido el Fondo Monetario Internacional (FMI) a partir de los primeros planes de ajuste en 1976, las tres renegociaciones de su deuda externa durante la década de los ochenta hasta la firma del Plan Brady, y el retorno a los mercados financieros en los años noventa.

Hasta hoy, ya son tres grandes crisis que han cimbrado la economía mexicana: la devaluación de la moneda en 1976, la crisis de la deuda externa de 1982 y la crisis bancaria de 1994. Estos tres momentos muestran el desenvolvimiento de la economía nacional como uno de los experimentos mejor llevados por las autoridades del Banco Central, no sólo por los planes de 
ajuste y el pago a los acreedores a tasas de interés por arriba de la tasa promedio a nivel internacional, sino por los condicionantes estipulados en las firmas de los convenios de estabilización.

La firma del primer plan de estabilización del gobierno mexicano con las autoridades del FMI condicionó el financiamiento de una empresa estratégica para la economía mexicana, pero necesaria a los intereses de Estados Unidos en su momento. Petróleos Mexicanos (Pemex), líder en el sector petrolero, permitió satisfacer las reservas de petróleo al Pentágono en un entorno donde la Organización de los Países Productores de Petróleo (OPEP) tenía el liderazgo de las reservas y de los precios del petróleo en el ámbito internacional. El plan de estabilización sentó las bases de la fragilidad financiera en el corto plazo.

Al subir las tasas de interés de la Fed y la sobreoferta del petróleo en el mercado mundial incidió en la caída brutal de las exportaciones petroleras de nuestro país, y el servicio de la deuda externa se manifestaría en una "crisis de caja" en agosto de 1982, que empujaron a un Plan de Salvamento negociado entre la Secretaría de Hacienda mexicana, el FMI, el Banco Mundial, la Fed, el Banco de Pagos Internacional y la compra anticipada de reservas petroleras nuevamente para Estados Unidos. Después de una reestructuración de la economía mexicana bajo los lineamientos del Consenso de Washington y la apertura indiscriminada de los circuitos financieros nacionales se presentaría la crisis bancaria mexicana, mencionada como la primera crisis global del siglo xxI.

México ha sido uno de los países del mundo cuya crisis bancaria mostró la estrecha relación entre los inversionistas institucionales, principalmente estadounidenses, y los bonos del gobierno mexicano, ${ }^{1}$ mismos que no pudieron dar estabilidad financiera, sino todo lo contrario. La frágil e inestable economía y el riesgo del país en un año electoral sucumbieron ante la incapacidad de un nuevo gobierno, cuya fuga de capitales no tuvo otra opción que la devaluación del peso en diciembre de 1994 y los planes de estabilidad se convirtieron en planes de austeridad.

Los recurrentes planes de austeridad, pasaron a ser una constante debido a los condicionantes macroeconómicos que impuso el TLCAN en materia de política monetaria, fiscal y financiera, no obstante, el alto precio del petróleo

1 Los llamados Tesobonos fueron creados por el gobierno mexicano para evitar mostrar los desajustes internos de la economía ante el recién firmado Tratado de Libre Comercio de América del Norte (TLCAN) 
permitió hacer frente al pago del servicio de la deuda externa sin mayor problema. El coeficiente servicio de la deuda externa con relación a las exportaciones petroleras mejoró y se hicieron pagos adelantados, incluso al FMI, entre 2005 y 2006. Un suspiro, antes de sucumbir.

México, al igual que otros países latinoamericanos, tuvo un boom económico y reformas sociales que disminuyeron los indicadores de pobreza no por su inclusión en los circuitos financieros, sino por la especulación del precio de sus exportaciones. Las economías de commodities, cuyos precios se vendieron en los mercados de futuros como derivados de alto rendimiento, fueron mermando una vez que se presentó la Crisis Subprime, antecedente de la Gran Crisis Financiera de 2007/2009.

La breve recuperación en 2009 por la intermediación de los bancos centrales creó nuevas burbujas y las soterradas políticas de austeridad ocasionaron una disminución del crecimiento. El FMI en sus reuniones de octubre de 2015 anunció un leve crecimiento, sin embargo, para la reunión de otoño de 2016 vuelven a caer los pronósticos del crecimiento. Ante esta situación, para países como México, se creó la Línea de Crédito Flexible (LCF) para evitar posibles desajustes y crisis económicas.

México fue el primer país beneficiado por un monto equivalente a $47 \mathrm{mil}$ millones de dólares (31500 millones de Derechos Especiales de Giro) en el marco de una LCF de carácter precautorio, previendo no utilizar los fondos y respondiendo al buen comportamiento de las políticas económicas que con firmeza ha aplicado el gobierno en palabras del FMI.

Después de esta LCF, México la ha renovado en 2010, 2011, 2012, 2014 y 2016. El primer acuerdo de México en el marco de la LCF fue aprobado el 17 de abril de 2009 por 47 mil millones de dólares y fue renovado el 25 de marzo de 2010 por 48 mil millones, y otras cuatro veces más, hasta llegar a una línea de crédito aprobada por 88 mil millones de dólares en mayo del 2016.

Es de esta manera como Carlos F. Díaz Alejandro con su trabajo seminal demuestra que los procesos de desregulación y liberalización financiera han llevado a la aplicación de políticas de austeridad que inciden en mayor endeudamiento incluso como las líneas precautorias adoptadas a partir del 2009 y hasta el día de hoy. Ante tal hecho, sólo resta preguntar ¿si las políticas económicas adoptadas son una alternativa viable o si son contrarias al desarrollo con equidad y sustentabilidad?.

La revista Problemas del Desarrolllo abre su número con el artículo "Reformas sociales en China: 2016-2020" de los autores Andoni Maiza y Ricardo Bustillo. China ha realizado una serie de reformas sociales en el marco del 
$13^{\text {er }}$ Plan Quinquenal 2016-2020 con el objeto de seguir siendo el eje dinámico a nivel internacional. Necesariamente se tiene que aumentar el empleo y los puestos de trabajo, así como los años de escolaridad, seguridad médica y seguro de desempleo. No por ello menos importante es la reforma de pensiones que abarque a los trabajadores rurales, quienes debido al sistema hukou se ven desfavorecidos frente a los trabajadores de las zonas urbanas. A ello, se suma la política del hijo único y el envejecimiento de una gran parte de la población. El salario promedio rural representa el $40 \%$ del salario promedio urbano, no obstante que ha sido triplicado frente a otros países del Sudeste asiático, sin embargo, sigue siendo considerado muy bajo y el desplazamiento de los puestos de trabajo se está trasladando a otros países de la región.

Por su parte, Manuel Pérez García en su artículo "Internacionalización y reformas del sistema de educación superior en China" aborda el tema de la "fuga de cerebros" y cómo ha afectado a países como China y la Unión Europea. Destaca la reforma en el sistema de educación superior en China basada en un proyecto de internacionalización que tiene por objeto una "nueva nacionalización del sector académico". Actualmente hay un número importante de estudiantes chinos viviendo en Estados Unidos reflejo de un mayor interés por este país de América que en la Unión Europea. Existe un esfuerzo de las principales universidades de China por consolidar una red de académicos en Europa, América Latina y África. El desenvolvimiento económico durante la última década ha fortalecido el interés por profundizar la cooperación de las instituciones académicas por expandir lazos desde un espacio global basado en la movilidad académica. En el largo plazo, el mutuo entendimiento redundará en un win-win para China, Europa y las regiones y países participantes.

La construcción de la hegemonía y el populismo en el kirchnerismo es resultado de la configuración de Argentina en el periodo de posconvertibilidad resultado de la crisis del Consejo Monetario comenta Gastón Ángel Varesi en su trabajo "Acumulación y hegemonía en Argentina durante el kirchnerismo". El periodo posconvertibilidad favoreció el modelo productivo-exportador ante un alza de los commodities, una política de ingreso favorecida por las retenciones hizo posible la disminución de la pobreza y la reestatización de empresas, reestructuración de la deuda externa mejorando los indicadores económicos y la ruptura con el FMI hicieron posible un pacto social. El periodo 2008-2011 se inicia con una fractura en el sector industrial, una crisis energética, menor participación de los conglomerados financieros, el impacto de la crisis económica mundial y un conflicto agrario que dieron origen a la conformación de una alternativa conservadora y liberal. 
"Ecuador en la trampa de la renta media" escrito por Rafael Domínguez y Sara Caria destaca hasta qué grado el Estado desarrollista puede superar la trampa de la renta media (TRM) convirtiéndose Ecuador en un ejemplo para otros países de América Latina. Un país cuyo desenvolvimiento económico se basa en la dependencia de productos primarios, donde predomina la explotación de recursos naturales, es un factor determinante del cambio estructural imperfecto. El Estado ha desarrollado un incremento en la inversión pública, educación e innovación cuyo impacto será a mediano plazo. El alto grado de dependencia de los precios de las exportaciones petroleras del ciclo económico mundial impacta en políticas fiscales procíclicas y la recurrente inestabilidad económica y política. Las políticas sociales han sido determinantes en el modelo económico mejorando el capital humano, así como la inversión en infraestructura ha logrado el avance del sector público. Aun así el cambio estructural es lejano todavía.

Edel J. Fresneda en su artículo "Cuba, desarrollo, dependencia y heterogeneidad estructural" aborda el desarrollo histórico de la isla a partir del triunfo de la Revolución que emerge en el contexto de la Guerra Fría en la década de los sesenta. El Estado asumió el control de la producción bajo el socialismo real y excluyó la capacidad endógena de estrategias propias de producción. La erradicación del sistema de propiedad privada borró la innovación empresarial y las cadenas de valor en un proceso de internacionalización a nivel mundial. La necesidad de inversión y de industrialización, así como los desequilibrios financieros, han requerido de endeudamiento externo para proteger a sectores sociales marginados. La reproducción de la dependencia externa y la heterogeneidad estructural propició un círculo vicioso que implica la ruptura del presente.

La refinación en México es el resultado del mal manejo de las políticas económicas ejercidas desde finales de los ańos setenta. Daniel Romo en su trabajo titulado "Refinación de petróleo en México y perspectiva de la Reforma Energética" manifiesta la falta de una política industrial acorde con las necesidades del país basada en los derivados del petróleo, mayores inversiones en el campo de la refinación en Petróleos Mexicanos (Pemex), y la decisión política de no impulsar otros medios de transporte, han terminado en una apertura indiscriminada a la importación de gasolina e impactando en un déficit en la balanza comercial petrolera. La Reforma Energética y la necesaria participación de empresas privadas no sólo deben de centrarse en la exportación de petróleo crudo, sino en la capacidad de procesarlo. Pemex como empresa líder en el ámbito nacional tendrá que jugar un papel determinante en la articulación 


\section{Editorial}

con el sector empresarial privado nacional e internacional para adecuarse a las necesidades que demanda el país.

Luis Huesca y Gloria Ochoa en su trabajo "Desigualdad salarial y cambio tecnológico en la Frontera Norte de México" abordan la apertura en el marco del TLCAN que ha motivado cambios en la estructura salarial y la composición del empleo relacionados con el impacto tecnológico en el mercado laboral. La desigualdad salarial en la Frontera Norte se estudia a partir de su clasificación en trabajadores calificados y no calificados, pero el artículo ofrece otra variante de clasificación por el tipo de tareas que realizan: abstractas, rutinarias y manuales. Al utilizar el índice de Gini en relación con las tareas señaladas se logra medir con mayor precisión los cambios en la desigualdad salarial obteniendo resultados interesantes del impacto tecnológico en el mercado laboral.

Alicia Girón

La Dirección de la Revista

Ciudad Universitaria, septiembre 2016 